\title{
Effect of Sintering Temperatures on Structural, Magnetic and Microwave Properties of Barium Ferrites/Epoxy Composites
}

\author{
Nurshahiera Rosdi, Raba'ah Syahidah Azis, Ismayadi Ismail, Muhammad Syazwan Mustaffa, \\ Nurhidayaty Mokhtar
}

\begin{abstract}
This research highlights the structural magnetic and microwave properties of nanoparticles of M-type hexagonal barium ferrites $\left(\mathrm{BaFe}_{12} \mathrm{O}_{19}\right)$. The samples were sintered at varied sintering temperatures $\left(800,900\right.$, and $\left.1000{ }^{\circ} \mathrm{C}\right)$. The effect of temperatures on the structural, magnetic and microwave properties was highlighted. Barium ferrites are well-known materials used for radar absorbing materials (RAM). RAM materials with good absorbing performance should have high permeability, small permittivity and high magnetic or dielectric loss at microwave frequency. High microwave absorption can be created effectively in magnetic materials, as well as wideband absorption. The structural, microstructural and microwave properties were analyzed via an X-ray Diffractometer (XRD), a Field Emission Scanning Electron Microscope (FESEM) and a Vector Network Analyzer (VNA), respectively. The XRD results showed a full phase hexagonal structure was formed in the samples sintered at 900 and $1000{ }^{\circ} \mathrm{C} . \mathrm{BaFe}_{12} \mathrm{O}_{19}$ composite with a thickness of $3 \mathrm{~mm}$ showed a minimum Reflection Loss (RL) at $-9.01 \mathrm{~dB}$ at a frequency of $9.16 \mathrm{GHz}$ at temperature $1000{ }^{\circ} \mathrm{C}$.
\end{abstract}

Keywords: Barium hexaferrite, High energy ball milling (HEBM), Structural and microstructural properties, Electromagnetic and Microwave properties.

\section{INTRODUCTION}

Hexagonal structure ferrites have excellent magnetic properties for use in electromagnetic wave absorber of RAM [1]. Among all types of ferrites, M-type hexaferrite, in particular $\mathrm{BaFe}_{12} \mathrm{O}_{19}$, has been observed to reveal the largest saturation magnetization, suitable permeability values, and planar anisotropic conduct in microwave properties. [2]. In recent years, the development of technology based on electromagnetic (EM) radiation phenomena has become crucial owing to their use in modern life and as important elements of a stealth defense system for military reasons.

Revised Manuscript Received on July 22, 2019.

Nurshahiera Rosdi, Ismayadi Ismail, Institute of Advanced Technology (ITMA), Universiti Putra Malaysia (UPM). Email: nurshahierarosdi5243@gmail.com, ismayadi@upm.edu.my

Raba'ah Syahidah Azis, Physics Department, Faculty of Science, Universiti Putra Malaysia (UPM). Email: rabaah@upm.edu.my

Muhammad Syazwan Mustaffa, Physics Department, Faculty of Science, Universiti Putra Malaysia (UPM). Email: mm_syazwan@upm.edu.my

Nurhidayaty Mokhtar, Physics Department, Faculty of Science, Universiti Putra Malaysia (UPM). Email: hidayaty@upm.edu.my
EM wave absorbers can efficiently decrease the reflection of these waves that have become more appealing to distinct apps, and thus generating concern in the field between many researchers [3]. Microwave absorbers are usually split into two classifications of dielectric and magnetic absorbent materials that communicate with the occurrence of electromagnetic waves at a particular frequency of electromagnetic waves with ferromagnetic resonance, leading in peak energy absorption from incident waves. [4]. In this study, barium hexagonal ferrites were studied on X-band $(8-12 \mathrm{GHz})$ frequencies. The effect of sintering temperatures on it's structural, microstructural and microwave properties were investigated.

In this works, $\mathrm{BaFe}_{12} \mathrm{O}_{19}$ was successfully prepared by using the simplest top down method which is HEBM. The nanocomposites then sintered with three different temperatures and were characterized by using XRD, FESEM, and VNA. With the good characteristics that presented, the nanocomposites would expect to have higher potential in absorbing materials applications.

\section{EXPERIMENTAL}

The raw materials which is hematite $\left(\mathrm{Fe}_{2} \mathrm{O}_{3}\right)$ and barium carbonate $\left(\mathrm{BaCO}_{3}\right)$ were weighed according to the stoichiometric ratio and ground using an agate mortar for $1 \mathrm{~h}$.

The raw ground powders were subjected to high energy ball milling using a SPEX800D HEBM machine for $6 \mathrm{~h}$ with the ball to powder (BPR) ratio 10:1 for high energy ball milling (HEBM). A Carbolite furnace was used to sinter all samples at 800,900 and $1000^{\circ} \mathrm{C}$ for $6 \mathrm{~h}$ at a rate of $3^{\circ} \mathrm{C} /$ min. At a concentration of 70:30 by weight, ground samples of hexaferrite $\mathrm{BaFe}_{12} \mathrm{O}_{19}$ were then combined with epoxy resin (Araldite 506 epoxy resin, Sigma Aldrich) and hardener as filler. The sample blend was then dried in a metal back with a 1,2 and $3 \mathrm{~mm}$ rectangular sample holder for $48 \mathrm{~h}$. X-ray diffraction, XRD (Philips X'pert Diffractometer model 7602 EA Almelo) studied the phase structure of the composite samples. The measurement was performed out at room temperature, with a diffraction angle $(2 \theta)$ between of $20^{\circ}$ to $80^{\circ}$. Using X'pert HighScore software, the information was assessed and contrasted with an electronic PDF2 library Using field emission scanning electron microscopy, FESEM (FEI Nova NanoSEM 230), the microstructure of $\mathrm{BaFe}_{12} \mathrm{O}_{19}$ composite samples was detected. 


\section{Effect of Sintering Temperatures on Structural, Magnetic and Microwave Properties of Barium Ferrites/Epoxy Composites}

Using a N5227A PNA network analyzer with using coaxial transmission / reflection technology, the complex permittivity, complex permeability and microwave absorbing characteristics of the prepared composite were performed (Fig. 1).
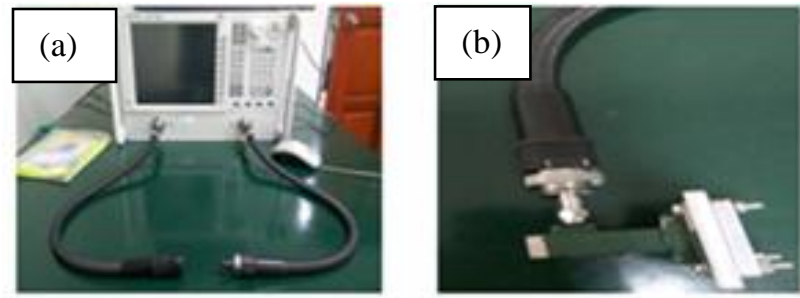

Fig. 1.Vector network analyzer (a), and (b) Sample holder with an adapter.

\section{RESULT AND DISCUSSION}

Fig. 2.indicates the XRD pattern of associated nanoparticles of barium hexaferrite; confirms the presence of well-coherent peaks. At $800{ }^{\circ} \mathrm{C}$, secondary phase which is hematite $\left(\mathrm{Fe}_{2} \mathrm{O}_{3}\right)$ was existed. The composition of a single phase $\mathrm{BaFe}_{12} \mathrm{O}_{19}$ without impurity started at the sintering temperatures of 900 and $1000^{\circ} \mathrm{C}$. The $\mathrm{Fe}_{2} \mathrm{O}_{3}$ phase has been diminished as the sintering temperatures were increased.

Table- I: Crystallite size of sintered $\mathrm{BaFe}_{12} \mathrm{O}_{19}$.

Temperatures, $\left({ }^{\circ} \mathrm{C}\right) \quad$ Crystallite size, $D(\mathrm{~nm})$

$\begin{array}{ll}800 & 42.6 \\ 900 & 50.9 \\ 1000 & 49.8\end{array}$

Table I shows the crystallite size of sintered $\mathrm{BaFe}_{12} \mathrm{O}_{19}$. Crystallite size $(D)$ was calculated using the Scherrer Eq. 1[5]:

$D=\frac{k \lambda}{\beta \cos \theta}$

The diffraction angle is larger for the sample sintered at $800{ }^{\circ} \mathrm{C}$ compared to those sintered at 900 and $1000{ }^{\circ} \mathrm{C}$. This is reflected by the decrease in the crystallite size of the samples (Eq. 1). Fig. 4.shows the variation relation parameters of the $d$-spacing, the full width of half maximum (FWHM), the crystallite size and height intensity of the highest peak at (114). The $d$-spacing for sample sintered at $800{ }^{\circ} \mathrm{C}$ is larger compared to those sintered at 900 and $1000{ }^{\circ} \mathrm{C}$. These shifts in the respective peak parameters show the rise in particle size as well as the increase in sintering temperatures. The X-ray patterns also reveal that the structural deformation of the samples increases as the temperature rises. This is obvious, the rising in height of the significant deforming peak at (114) (Fig. 3). The peak is heights between 1983 and 2248, with temperatures rising from 800 to $1000{ }^{\circ} \mathrm{C}$. This indicates that the crystallinity of the samples rises with temperature increase. The similar trend also reported in previous reports [6]- [9]. The FWHM was decreased as the sintering temperature increased owing to the increase in the crystal size of the samples.

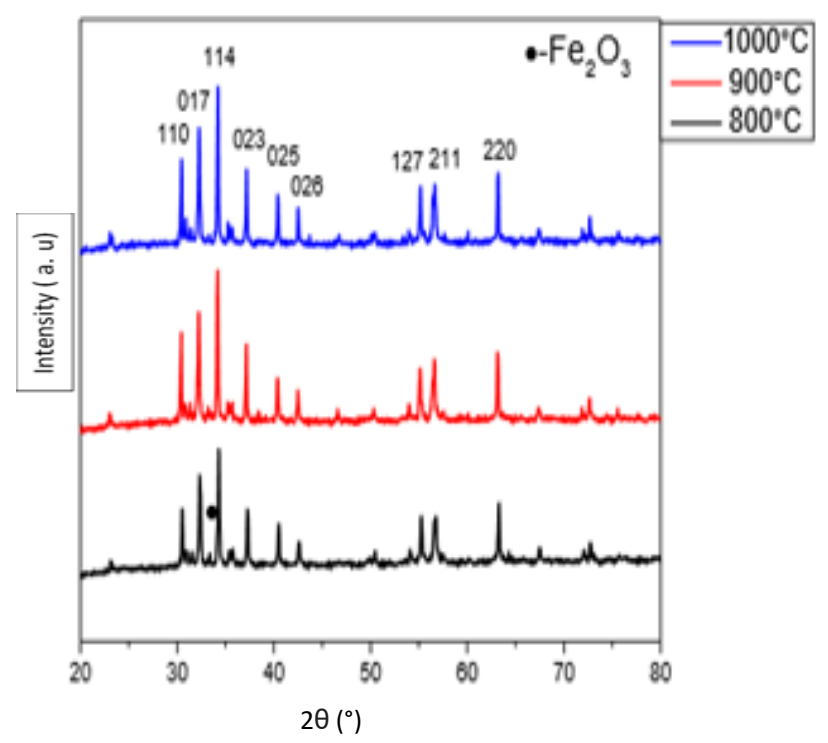

Fig. 2.X-ray diffraction pattern of $\mathrm{BaFe}_{12} \mathrm{O}_{19}$ at 800,900 and $1000{ }^{\circ} \mathrm{C}$.

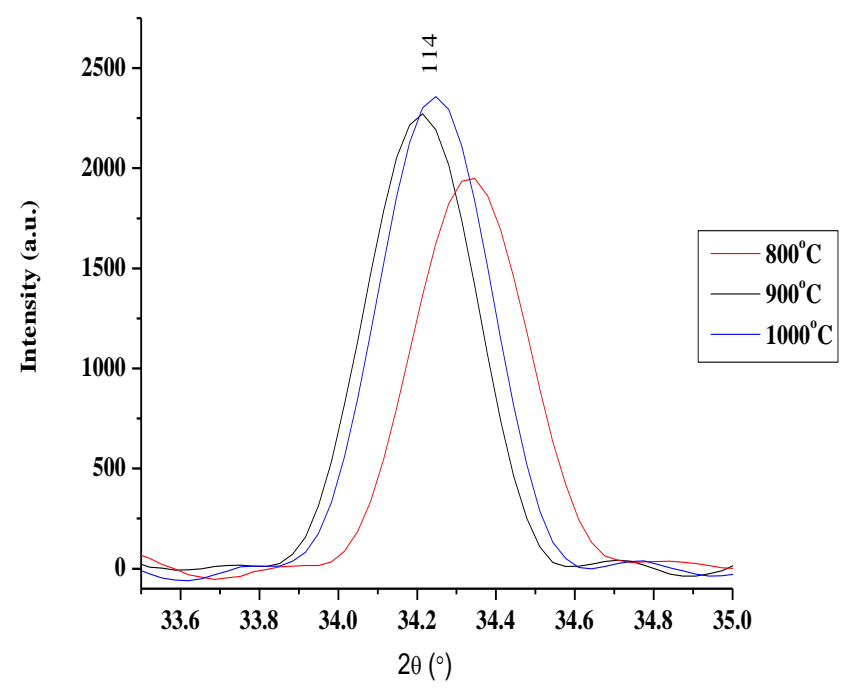

Fig. 3.XRD spectra at $2 \theta$ at the highest intensity (114). 
(a)
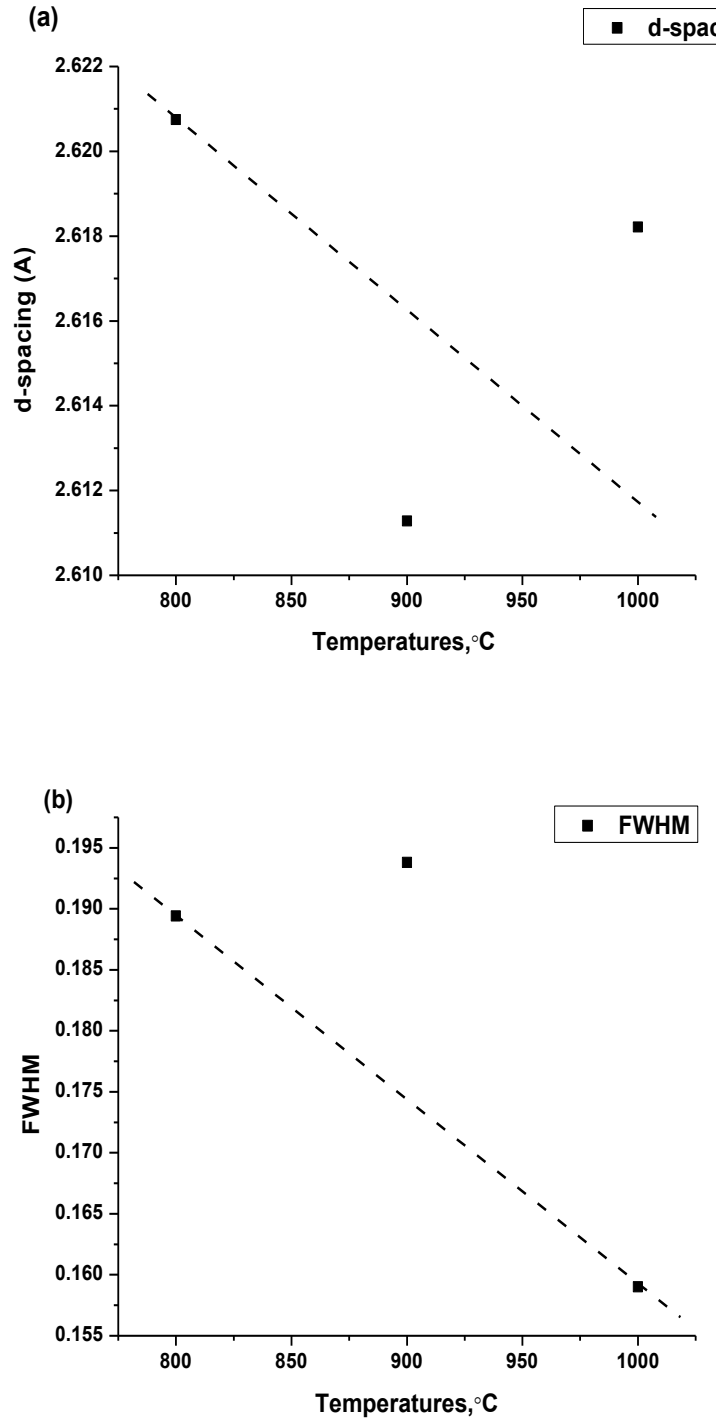

(c)

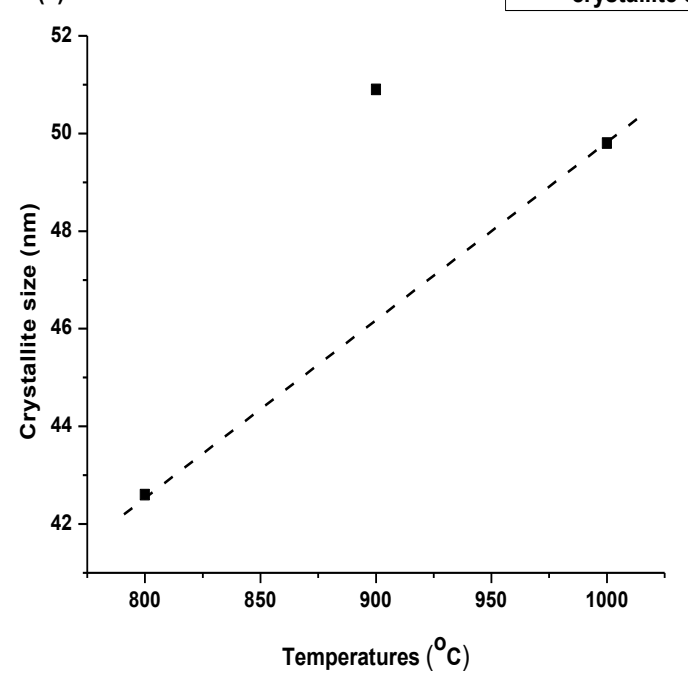

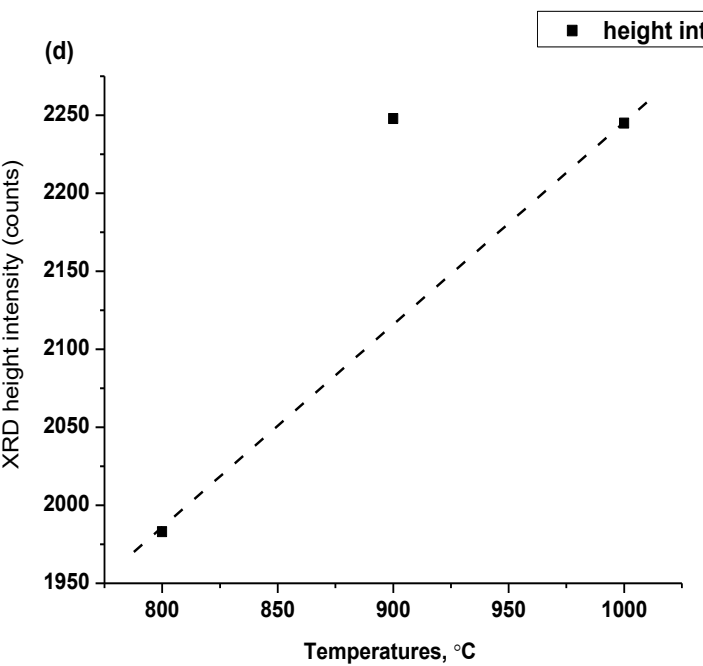

Fig. 4.Variation of $d$-spacing (a), full width of half maximum (FWHM) (b), the crystallite size (c), XRD height intensity of highest peak at (114) (d) of $\mathrm{BaFe}_{12} \mathrm{O}_{19}$ at various temperatures

Fig. 5.shows the morphology of $\mathrm{BaFe}_{12} \mathrm{O}_{19}$ nanoparticles powder sintered at $1000{ }^{\circ} \mathrm{C}$, examined using FESEM. The average grain size observed is $\sim 55 \mathrm{~nm}$ and is usually spherical in form and agglomerated owing to its magnetic nature.

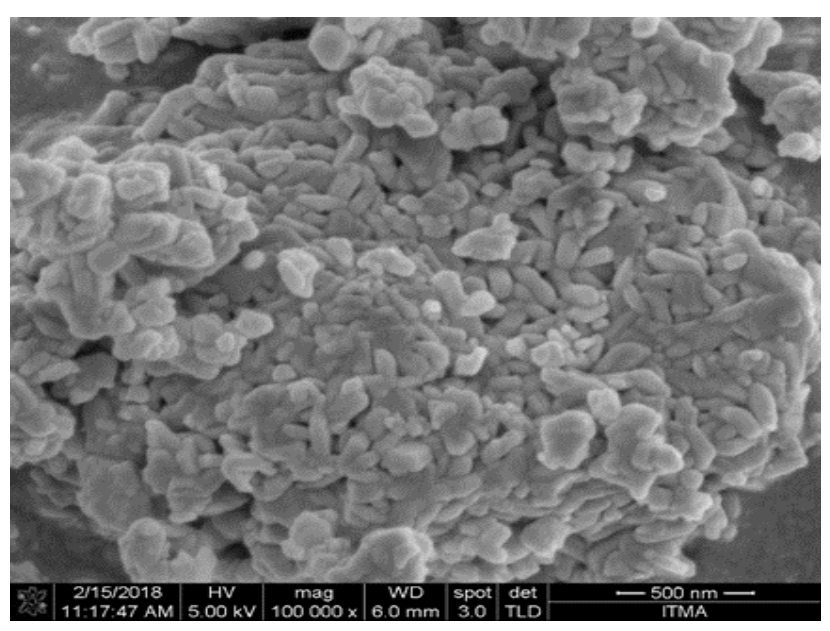

Fig. 5.FESEM image of $\mathrm{BaFe}_{12} \mathrm{O}_{19}$ at $1000{ }^{\circ} \mathrm{C}$.

Fig. 6.indicates the minimum reflection loss, RL approximately $-9.01 \mathrm{~dB}$ at a corresponding frequency of $9.16 \mathrm{GHz}$ at $1000{ }^{\circ} \mathrm{C}$ sintered sample (Table II) with a thickness of $3 \mathrm{~mm}$. It is clearly shown that the RL was enhanced as the sintering temperature rises owing to improved stoichiometry and crystallinity [10]- [12]. The much higher absorption is expected to occur at a much higher frequency due to a higher anisotropy field of $\mathrm{BaFe}_{12} \mathrm{O}_{19}$. At $\mathrm{X}$-band $(8-12 \mathrm{GHz})$ frequency, the barium ferrite shows the dielectric and magnetic permeability properties with low attenuation ability [13]. 
Effect of Sintering Temperatures on Structural, Magnetic and Microwave Properties of Barium Ferrites/Epoxy Composites

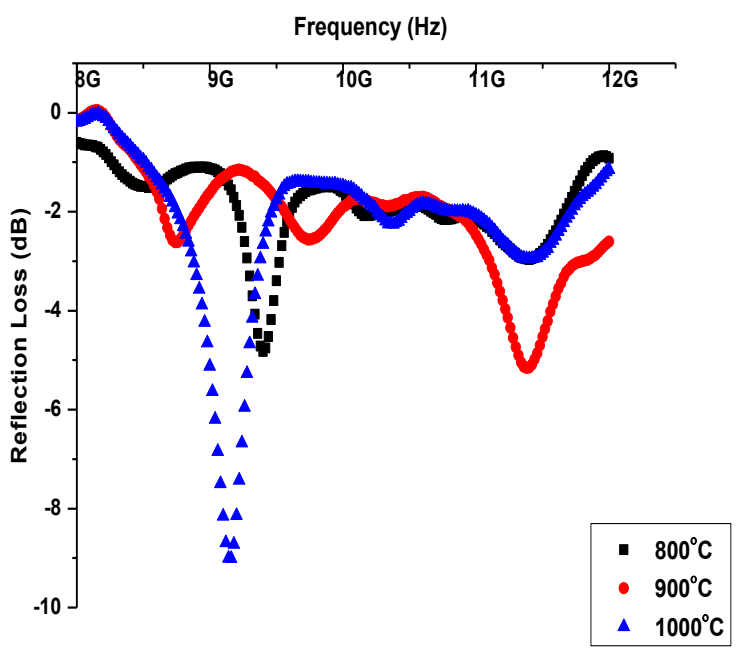

Fig. 6.Frequency dependency of reflection loss value of $\mathrm{BaFe}_{12} \mathrm{O}_{19}$ composite at $3 \mathrm{~mm}$ thickness with different sintering temperature.

Table- II: Electromagnetic wave absorption properties of $\mathrm{BaFe}_{12} \mathrm{O}_{19}$.

\begin{tabular}{ccc}
\hline $\begin{array}{c}\text { Temperatures } \\
\left({ }^{\circ} \mathrm{C}\right)\end{array}$ & $\begin{array}{c}\text { Peak value } \\
f_{m}(G H z)\end{array}$ & $\begin{array}{c}\text { Minimum } \\
\text { RL value } \\
(\mathrm{dB})\end{array}$ \\
\hline 800 & 9.40 & -4.82 \\
900 & 11.40 & -5.15 \\
1000 & 9.16 & -9.01 \\
\hline
\end{tabular}

Fig. 7.(a) and (b) showed the real and imaginary permeability ( $\mu^{\prime}$ and $\mu$ ') for 800,900 and $1000{ }^{\circ} \mathrm{C}$ sintered samples at thickness $3 \mathrm{~mm}$ at $8-12 \mathrm{GHz}$ respectively. There was shown the dependence of sintering to $\mu$ ' and $\mu$ " values in which the value of $\mu$ ' of permeability for all temperature are varied as increase the sintering temperatures. As for $\mu$ ", losses throughout the measured frequency stayed considerably continuous. The resonance peaks, however, happened between $8.5-11.5 \mathrm{GHz}$ ranges. The variation of permeability with respect to the frequency can be attributed to the rotation of spins or the displacement of the domain wall. Large $\mu$ " are expected as a microwave absorber that allows for excellent absorption of incident radiation. Highlights of the microwave behavior of magnetic materials are precession, resonance and relaxation.
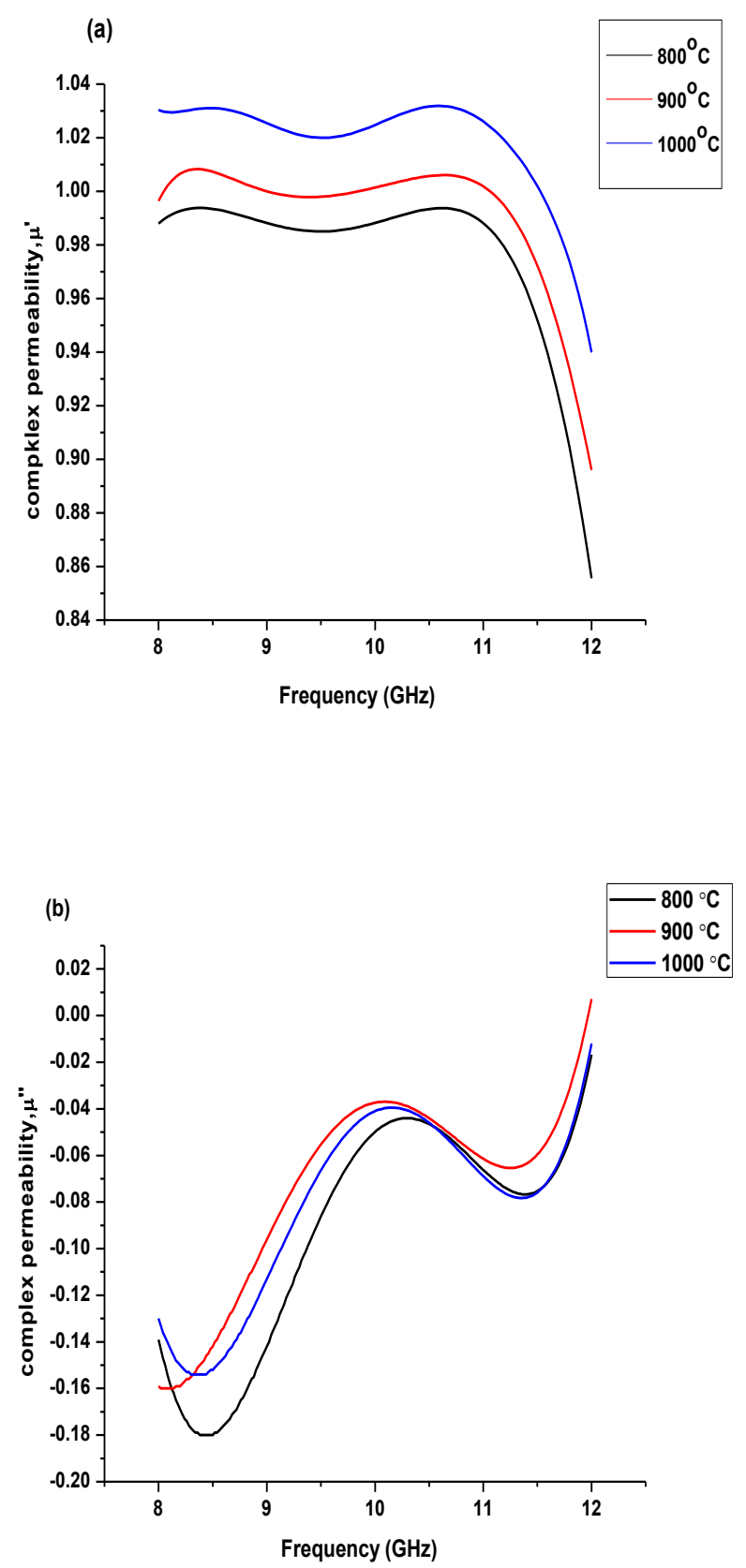

Fig. 7.Real (a) and imaginary (b) permeability of $\mathrm{BaFe}_{12} \mathrm{O}_{19} /$ epoxy composites.

\section{CONCLUSION}

In summary, $\mathrm{BaFe}_{12} \mathrm{O}_{19}$ was effectively prepared using a method of high-energy ball milling followed by sintering at different temperatures of 800,900 and $1000{ }^{\circ} \mathrm{C}$. The XRD analysis revealed the crystal structure of the hexagonal $\mathrm{M}$-type phase, $\mathrm{BaFe}_{12} \mathrm{O}_{19}$, with the space group $\mathrm{P}_{3} / \mathrm{mmc}$. The reflection loss peak showed the characteristic of maximum energy absorption of more than $50 \%(-9.01 \mathrm{~dB})$ at a frequency $9.16 \mathrm{GHz}$ when the sample thickness was $3 \mathrm{~mm}$ at a temperature of $1000{ }^{\circ} \mathrm{C}$. 


\section{ACKNOWLEDGMENT}

The authors are thankful for grants from Universiti Putra Malaysia (UPM), Inisiatif Putra Berkumpulan (IPB) GPB/2017/9541600, GP/2018/ 9628400 and IPS Putra research grant, UPM/ 800-3/3/1/(GP- IPS/2017/9533300, GP-IPS/2017/9539100. The authors also thanks to the Fundamental Research Grant Scheme (FRGS) and Long-term Research Grant Scheme [LRGS/ B-U/ 2013/ UPNM/ Defence \& Security-P2], Malaysian Ministry of Higher Education (MOHE).

\section{REFERENCES}

1. Alam, R. S., Moradi, M., Rostami, M., Nikmanesh, H., Moayedi, R., \& Bai, Y., "Structural, magnetic and microwave absorption properties of doped Ba-hexaferrite nanoparticles synthesized by co-precipitation method", Journal of Magnetism and Magnetic Materials, vol. 381, no. 1, 2015, pp. 1-9.

2. Amin, M. B., \& James, J. R., "Techniques for utilization of hexagonal ferrites in radar absorbers. Part 1: Broadband planar coatings", Radio and Electronic Engineer, vol. 51, no. 5, 1981, pp. 209-218.

3. Rusly, S. N. A., Matori, K. A., Ismail, I., Abbas, Z., Awang, Z., Zulkimi, M. M. M.v\& Zulfikri, N. D. (2018), "Microwave absorption properties of single-and double-layer coatings based on strontium hexaferrite and graphite nanocomposite," Journal of Materials Science: Materials in Electronics, vol. 29, no. 16, 2018, pp. 14031-14045.

4. Syazwan, M. M., Azis, R. S., Hashim, M., Ismayadi, I., Kanagesan, S., \& Hapishah, A. N, "Co-Ti-and Mn-Ti-substituted barium ferrite for electromagnetic property tuning and enhanced microwave absorption synthesized via mechanical alloying", Journal of the Australian Ceramic Society, vol. 53, no. 2, 2017, pp. 465-474.

5. Mustaffa, M. S., \& Shahrani, N. M. M, "Sintering Temperature Effect on Microstructure and Magnetic Evolution Properties with Nano-and Micrometer Grain Size in Ferrite Polycrystals", Sintering Technology: Method and Application, 2018, pp. 45

6. Ghufron, M., Baqiya, M. A., Mashuri, M., Triwikantoro, T., \& Darminto, D, "Phase Transition in Fe3o4/fe2o3 Nanocomposites by Sintering Process", Jusami| Indonesian Journal of Materials Science, vol. 12, no. 2, 2018, pp. 120-124.

7. M. A. Musa, R. S. Azis, N. H. Osman, J. Hassan, T. Zangina, "Structural and magnetic properties of yttrium iron garnet (YIG) and yttrium aluminum iron garnet (YAlG) nanoferrite via sol-gel synthesis". Results in Physics 7 ,2017, pp. 1135-1142.

8. R. S. Azis, M. M. Syazwan, N. M. M. Shahrani, A. N. Hapishah, R. Nazlan, F. M. Idris, I. Ismail, M. M. M. Zulkimi, I. R. Ibrahim, Z. Abbas, N. M. Saiden, "Influence of sintering temperature on the structural, electrical and microwave properties of yttrium iron garnet (YIG)", Journal of Materials Science: Materials in Electronics, vol. 29, no. 10,2018, pp. 8390-8401.

9. R. S. Azis, N. N. C. Muda, J. Hassan, A. H. Shaari, I.R.Ibrahim, M. S. Mustaffa, S. Sulaiman, K. A. Matori and Y. W. Fen, "Effect of Ratio in Ammonium Nitrate on the Structural, Microstructural, Magnetic, and AC Conductivity Properties of $\mathrm{BaFe}_{12} \mathrm{O}_{19}$," Materials, vol. 11, no. 11,2018, pp. 2190-2212

10. Rosdi, N., Mustaffa, M. S., Abdullah, N. H., Sulaiman, S., \& Ling, T. T, "Synthesis and characterization of $\mathrm{Mg}$-Ti substituted barium hexaferrite (BaMg 0.6 Ti 0.6 Fe 10.8 O 19) derived from millscale waste for microwave application", Journal of Materials Science: Materials in Electronics, vol. 30, no. 9, 2019, pp. 8636-8644.

11. M.M. Syazwan \& R.S. Azis \& M. Hashim \& I. Ismayadi \& S. Kanagesan \& A.N. Hapishah, "Co-Ti- andMn-Ti-substituted barium ferrite for electromagnetic property tuning and enhanced microwave absorption synthesized via mechanical alloying", Journal of the Australian Ceramic Society, vol. 53, no. 2,2017, pp. 465-474.

12. M. M. Syazwan, M. Hashim, R. S. Azis, I. Ismail, S. Kanagesan, N. Hapishah, "Enhancing absorption properties of $\mathrm{Mg}-\mathrm{Ti}$ substituted barium hexaferrite nanocomposite through the addition of MWCNT", Journal of Materials Science: Materials in Electronics, Vol. 28, no. 12,2017, pp. 8429-8436.

13. Wang, Z., Wu, L., Zhou, J., Cai, W., Shen, B., \& Jiang, Z., "Magnetite nanocrystals on multiwalled carbon nanotubes as a synergistic microwave absorber", The Journal of Physical Chemistry C, vol. 117, no. 10,2013 , pp. 5446-5452.

\section{AUTHORS PROFILE}

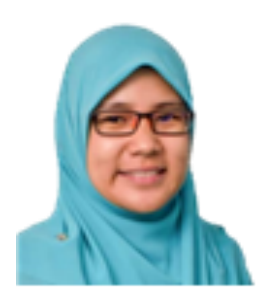

Nurshahiera Rosdi, a Master student of Materials Synthesis and Characterization Laboratory (MSCL) at the Institute of Advanced Technology (ITMA), Universiti Putra Malaysia (UPM). Her research interest is in magnetic materials and nanomaterials for the application of microwaves absorber.

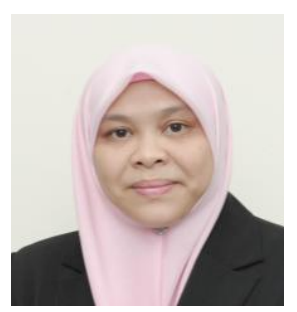

Raba'ah Syahidah Azis (PhD) is an Associate Professor at the Department of Physics, Universiti Putra Malaysia. She is an Associate Researcher at the Material Synthesis and Characterization Laboratory (MSCL), Institute of Advanced Materials (ITMA), UPM. Currently, she is an Auditor of Malaysian Solid State Science and Technology (MASS). Her research interests are material synthesis and characterization specialized in magnetic materials, nanomaterial, ferrites, sintering, and microstructure. Current research interest involves magnetic material and nanomaterials for microwave absorber and wastewater application.

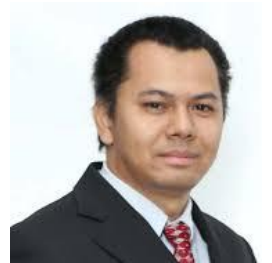

Ismayadi Ismail (Ph.D.), Reseach Officer Researcher Institute of Advanced Materials (ITMA), Universiti Putra Malaysia. He is also an active member of Malaysian Solid State Science and Technology (MASS). His research skills and expertise are material characterizations, materials, nanomaterial, and microstructure.

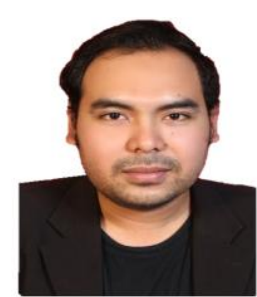

Muhammad Syazwan Mustaffa (Ph.D.) is a Postdoctoral staff at the Department of Physics, Universiti Putra Malaysia (UPM). His research skills and expertise are material characterizations, materials, nanomaterials, and microstructure. His current interest involves magnetic material for microwave absorber and wastewater application.

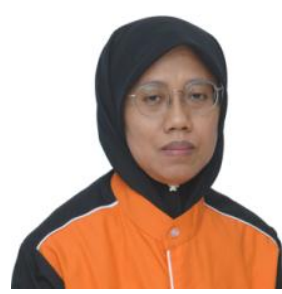

Nurhidayaty Mokhtar (Ph.D), is a senior lecturer at the Department of Physics, Universiti Putra Malaysia. Her current research skills and expertise are magnetic material, nanomaterials, and the microwave absorber applications. 